\title{
Effect of Drought on Agronomic Traits of Rice and Wheat: A Meta-Analysis
}

\author{
Jinmeng Zhang ${ }^{1,2} \mathbb{C}^{\mathbb{D}}$, Shiqiao Zhang ${ }^{1,2}$, Min Cheng ${ }^{1,2} \mathbb{C}^{\circ}$, Hong Jiang ${ }^{1,2,3, *}$, Xiuying Zhang ${ }^{1,2}$, \\ Changhui Peng ${ }^{4}$, Xuehe Lu ${ }^{1,2}$, Minxia Zhang ${ }^{1,2}$ and Jiaxin Jin ${ }^{5}$ \\ 1 International Institutes for Earth System Science, Nanjing University, Nanjing 210023, China; \\ beike0922@163.com (J.Z.); zhangshiqiao3039@163.com (S.Z.); chengmin007008@163.com (M.C.); \\ lzhxy77@163.com (X.Z.); luxh@nju.edu.cn (X.L.); 18357173715@163.com (M.Z.) \\ 2 Jiangsu Provincial Key Laboratory of Geographic Information Science and Technology, Nanjing University, \\ Nanjing 200023, China \\ 3 School of Forestry \& Bio-Technology, Zhejiang A\&F University, Lin'an 311300, China \\ 4 Institute of Environment Sciences, Department of Biology Sciences, University of Quebec at Montreal, \\ Montreal, QC H3C 3P8, Canada; peng.changhui@uqam.ca \\ 5 School of Earth Sciences and Engineering, Hohai University, No. 8 Fo cheng xi Road, Nanjing 211100, China; \\ jiaxinking@126.com \\ * Correspondence: jianghong@nju.edu.cn; Tel.: +86-025-8968-5969
}

Received: 20 March 2018; Accepted: 17 April 2018; Published: 24 April 2018

\begin{abstract}
Drought has been one of the most important limiting factors for crop production, which deleteriously affects food security worldwide. The main objective of the present study was to quantitatively assess the effect of drought on the agronomic traits (e.g., plant height, biomass, yield, and yield components) of rice and wheat in combination with several moderators (e.g., drought stress intensity, rooting environment, and growth stage) using a meta-analysis study. The database was created from 55 published studies on rice and 60 published studies on wheat. The results demonstrated that drought decreased the agronomic traits differently between rice and wheat among varying growth stages. Wheat and rice yields decreased by $27.5 \%$ and $25.4 \%$, respectively. Wheat grown in pots showed greater decreases in agronomic traits than those grown in the field. Rice showed opposite growing patterns when compared to wheat in rooting environments. The effect of drought on rice increased with plant growth and drought had larger detrimental influences during the reproductive phase (e.g., blooming stage, filling stage, and maturity). However, an exception was found in wheat, which had similar decreased performance during the complete growth cycle. Based on these results, future droughts could produce lower yields of rice and wheat when compared to the current drought.
\end{abstract}

Keywords: drought; crop; yield; agronomic traits; meta-analysis

\section{Introduction}

Drastic climate changes and increased water scarcity challenge global food security, which is further exacerbated due to the need to feed a growing global population [1]. A reviewed estimate states that global agricultural production might need to increase by $60-110 \%$ to meet the increasing demands [2] as well as to provide food security to the predicted 870 million people who will be chronically undernourished by 2050 [3]. However, the rates of global crop production are far below the amounts required to meet projected demands by $2050[4,5]$. Crop yield is affected by agronomic factors and various environmental variables such as water availability and temperature $[6,7]$. There is extensive crop yield variability in many semi-arid regions, which are owed to water limitation 
and year-to-year fluctuations in meteorological conditions. Although an increase in temperature is beneficial for crop productivity in some cooler regions of the world, drought still significantly reduces national cereal production by $9-10 \%$ on a global scale [1] via negative effects on plant growth, physiology, and grain development [8-10]. Caused by reduced precipitation and increased temperature [11], drought has been the most important limiting factor for crop productivity and, ultimately, for food security worldwide [12]. Wheat (Triticum aestivum L.) and rice (Oryza sativa L.) are two of the three major global cereals (wheat, rice, and maize (Zea mays L.)) with global annual productions of 713.2 and 745.7 million tons, respectively. Wheat and rice contributed more than $50 \%$ to global cereal production in 2013 [13]. Previous studies have revealed that their grain yields have declined in recent years because of drought. These studies have included several meta-analyses, summary studies, and model simulation results with only drought taken into account or an interaction with temperatures (see Table 1). It will be necessary to increase biomass production and economic yield under the conditions constrained by climate and water availability [14]. However, before this can occur, the extent of wheat and rice yield reduction and other agronomic traits that are affected by changes in the climate must be understood.

Table 1. Yield losses in wheat and rice caused by drought.

\begin{tabular}{|c|c|c|c|}
\hline Crop Species & Stress and Description & Yield Losses (\%) & Reference \\
\hline \multirow{7}{*}{ Wheat (Triticum aestivum L.) } & $\begin{array}{l}\text { Drought taken as } 40-45 \% \text { of } \\
\text { soil natural water content } \\
\text { (NWC: } 100 \% \text { ) }\end{array}$ & 57 & Balla et al., 2011 [15] \\
\hline & $\begin{array}{l}\text { Drought taken as } \\
\text { approximately } 40 \% \text { of soil } \\
\text { water reduction }\end{array}$ & 20.6 & Daryanto et al., 2016 [13] \\
\hline & $\begin{array}{l}\text { Drought, water stress } \\
\text { ( } \sim 40 \% \text { water deficit) }\end{array}$ & $<25$ & Daryanto et al., 2017 [12] \\
\hline & $\begin{array}{l}\text { Drought, tenth-percentile } \\
\text { rainfall outcome }\end{array}$ & 22 & Tavk et al., 2014 [16] \\
\hline & $\begin{array}{l}\text { Drought and warming } \\
\left(1^{\circ} \mathrm{C} \text { warming }\right)\end{array}$ & 33 & Tavk et al., 2014 [16] \\
\hline & $\begin{array}{l}\text { Drought, the SPEI } \\
\text { (Standardized Precipitation } \\
\text { Evapotranspiration Index) } \\
\text { denoting extreme dry } \\
(0.05 \text { quantile) }\end{array}$ & 4.4 & Matiu et al., 2017 [9] \\
\hline & $\begin{array}{l}\text { Drought and high } \\
\text { temperature, a } 1^{\circ} \mathrm{C} \text { higher } \\
\text { than average global } \\
\text { temperature }\end{array}$ & 9.2 & Matiu et al., 2017 [9] \\
\hline \multirow{3}{*}{ Rice (Oryza sativa L.) } & $\begin{array}{l}\text { Drying, soils dried beyond } \\
-20 \mathrm{kPa}\end{array}$ & 22.6 & Carrijo et al., 2017 [17] \\
\hline & $\begin{array}{l}\text { Drought, a period of water } \\
\text { deficit when the soil water } \\
\text { content declined below } \\
\text { saturation }\end{array}$ & $53-92$ & Lafitte et al., 2007 [18] \\
\hline & $\begin{array}{l}\text { Drought, water stress } \\
\text { ( } \sim 40 \% \text { water deficit) }\end{array}$ & $>50$ & Daryanto et al., 2017 [12] \\
\hline
\end{tabular}

Now, more than ever, the effect of drought on agronomic traits of rice and wheat has become more significant. With a changing climate, droughts are predicted to become more intense and frequent in many regions [19] with global agricultural drought frequency and area increasing by 
$50 \%$ to $200 \%$ during the 21 st century so far [20]. Therefore, a number of independent studies have investigated the individual effects of drought on wheat and rice agronomic traits during different growth stages. The severity and duration of drought stress determine the extent of the yield loss by shortening the life cycle and duration of grain filling [8]. Leilah et al. [21] found that the panicle number, grain weight, and biological yield were the most effective variables that influenced grain yield in a wheat cultivar. Grain yield and yield components of rice have also been examined in relation to drought occurring at various stages of growth [22]. A change in any agronomic traits under drought conditions alters the final crop yield including the growth parameters (e.g., plant height and biomass at harvest) and components of harvestable yield such as the panicle number per unit area (PNPU), the grain number per panicle (GNPP), 1000-grain weight (GW), the panicle length (PL), and the filled grain percentage/seed setting rate (FP). However, the effect of these parameters across different crop groups and drought conditions has not been fully elucidated. Nonetheless, this information is required for developing agricultural practices aimed at minimizing the effect of drought. Furthermore, this information would improve the accuracy of crop-simulation models to evaluate the effects of projected climate change on crop yields.

The diversity of drought effects on agronomic traits of rice and wheat are too complex to compare using traditional methods. Therefore, meta-analysis was used in the present study to identify general trends among numerous independent drought-related studies and combine the results into one measure known as the effect size [23]. Meta-analysis has been used to study the response of wheat and rice to elevated $\mathrm{O}_{3}$ and $\mathrm{CO}_{2}[24,25]$ levels as well as to synthesize a crop production response to drought on a global scale [12,13]. In the present study, we conducted a meta-analysis assessment to summarize and synthesize the results of the numerous studies for agronomic traits such as growth as well as grain yield and its components of rice and wheat in response to drought. Furthermore, we explored the sources of variation among these two crops in response to drought. Our aim was to answer the following questions. To what extent is rice and wheat grain yield reduced by drought and how do the yield components respond to drought? Are the responses to drought dependent on growth stages, the rooting environment, and drought stress intensities? Do the wheat types lead to differences in wheat agronomic traits? Hopefully, the results can improve our quantitative understanding of the effect of drought on rice and wheat and help minimize the influence of drought on crop production. This will improve the accuracy of crop-simulation models that are used to evaluate the effects of projected climate change on crop yields.

\section{Materials and Methods}

\subsection{Data Collection}

Using the Web of Science (Thompson-ISI, Philadelphia, PA, USA) and the China Knowledge Resource Integrated Databases, a survey on the wheat and rice response to drought from 1980 to 2017 was completed. The database was built based on keywords such as wheat or rice, water stress, water deficit, drought, growth, yield, and productivity. Only studies that met the following selected criteria were included in the database: (1) involved plants that experienced drought under field conditions and pot studies, (2) the reported effect data of a water deficit was taken from the experiments including two datasets of a well-watered control group and a drought condition treatment group without other treatments (e.g., addition of fertilizer, modification of temperature, $\mathrm{CO}_{2}$ or $\mathrm{O}_{3}$ ), (3) contained any of the plant growth parameters of rice and wheat listed in Table 2, and (4) included replication in the experimental design. Data from the figures were digitized using data extraction software (Plot Digitizer-Windows). In total, 120 cultivars from 60 published wheat studies and more than 70 cultivars from 55 published rice studies were used in the global meta-analysis, which excluded all additional treatments (see Table S1). 
Table 2. List and description of response variables reported in the meta-analysis study.

\begin{tabular}{|c|c|c|c|}
\hline \multicolumn{2}{|r|}{ Agronomic Traits } & \multicolumn{2}{|r|}{ Growth Stage } \\
\hline Variable & Description & Variable & Description \\
\hline Yie & Yield, grain weight per plant or per $\mathrm{m}^{2}$ & Gc & $\begin{array}{l}\text { Drought during both the vegetative and } \\
\text { reproductive phases or the complete } \\
\text { growth cycle }\end{array}$ \\
\hline PH & Plant height & Fs & $\begin{array}{l}\text { Drought occurring at filling stage or } \\
\text { grain-filling stage }\end{array}$ \\
\hline $\begin{array}{l}\text { PL } \\
\text { GW }\end{array}$ & $\begin{array}{l}\text { Panicle lengt or ear length } \\
\text { 1000-grain weight }\end{array}$ & Bls & $\begin{array}{l}\text { Drought occurring at blooming stage or } \\
\text { from blooming stage to maturity }\end{array}$ \\
\hline $\begin{array}{l}\text { FP } \\
\text { Bio }\end{array}$ & $\begin{array}{l}\text { Filled grains percentage or seed setting } \\
\text { rate } \\
\text { Total biomass per plant at harvest }\end{array}$ & Hs & $\begin{array}{l}\text { Drought occurring at heading stage or } \\
\text { from heading to maturity }\end{array}$ \\
\hline GNPP & Grain number per panicle & $B s$ & Drought occurring at booting stage \\
\hline \multirow[t]{2}{*}{ PNPU } & Panicle number per plant or $\mathrm{m}^{2}$ & Js & $\begin{array}{l}\text { Drought occurring at jointing stage or } \\
\text { from jointing stage to maturity }\end{array}$ \\
\hline & & Ts & Drought occurring at tillering stage \\
\hline
\end{tabular}

The magnitude of crop responses to drought was examined based on the following categorical variables: (i) cereal species (wheat and rice), (ii) agronomic traits (see Table 2), (iii) drought timing or growth stages (see Table 2; productive phase included blooming and grain filling stages while the vegetative phase included jointing and booting stages); (iv) wheat types (winter wheat versus spring wheat); (v) drought stress intensity (mild, moderate, and severe), relative soil water content (RSWC), or soil water potential (SWP); and (vi) root environment (plants grown in the field, plot, and pot). These groups were used as moderators in the meta-analysis to distinguish effect size values.

For the meta-analysis in the present study, we focused on the effect of drought on rice and wheat agronomic traits. Therefore, only selected studies with the single effect of water deficit were included. We only selected data from the studies with paired groups (i.e., control and treatment) and, therefore, we considered that other environmental factors (e.g., temperature, light intensity, and $\mathrm{CO}_{2}$ concentration) were the same between the control and drought conditions. Drought intensity was classified into three levels (mild, moderate, and severe) based on the description in the studies. If drought intensity had not been elaborated on in the study, it was classified based on the RSWC including mild stress $(55 \%<$ RSWC $<70 \%)$, moderate stress $(35 \%<$ RSWC $<55 \%)$, and severe stress (RSWC $<35 \%$ ) and according to the SWP (mild stress $(-35 \mathrm{kPa}<\mathrm{SWP}<-10 \mathrm{kPa}$ ), moderate stress $(-55 \mathrm{kPa}<\mathrm{SWP}<-35 \mathrm{kPa})$, and severe stress (SWP $<-55 \mathrm{kPa})$ ).

\subsection{Meta-Analysis}

The effect size for each observation was calculated as the natural $\log$ of the response ratio (R) to represent the magnitude of the responses of agronomic traits to drought [23,26].

$$
\mathrm{R}=\ln \left(\mathrm{X}_{\mathrm{e}} / \mathrm{X}_{\mathrm{c}}\right)=\ln \left(\mathrm{X}_{\mathrm{e}}\right)-\ln \left(\mathrm{X}_{\mathrm{c}}\right)
$$

where $X_{e}$ and $X_{c}$ are the mean response values of each individual observation in the treatment and control groups, respectively. Not all of the studies reported the mean values for the treatment and control conditions by reporting standard deviations or standard error values. Therefore, we used an unweighted meta-analysis as described in previous studies to maximize the number of observations in the studies [27]. The mean effect size of each categorical subdivision was calculated by the equation below.

$$
\overline{\mathrm{R}}=\sum(\mathrm{R}) / \mathrm{N}
$$


where $N$ is the number of samples. Then the $\bar{R}$ was reported as the percent change (D, \%) [25], which is more visible than $\bar{R}$ and was calculated by the equation below.

$$
\mathrm{D}(\%)=\left(\mathrm{e}^{\overline{\mathrm{R}}}-1\right) \times 100 \%
$$

If the 95\% confidence intervals (CI) of the percent change do not overlap with zero [24,25], this represents that the drought had a significant effect on the agronomic traits. The heterogeneity $\left(\mathrm{Q}_{b}\right)$ for each categorical variable was determined for the response variable (see Table 3 ). The significant $\mathrm{Q}_{\mathrm{b}}$ value indicated that the effect size was different between different agronomic traits. Figures were graphed using the Origin Pro 9.0 software program in Microsoft Windows.

Table 3. Heterogeneity $\left(Q_{b}\right)$ analysis of agronomic traits in rice and wheat.

\begin{tabular}{cccccccccc}
\hline Crop & $\begin{array}{c}\text { Categorical } \\
\text { Variable }^{\mathbf{a}}\end{array}$ & $\mathbf{Q}_{\mathbf{b}}$ & $\mathbf{N}$ & $\boldsymbol{p}$-Value & Crop & $\begin{array}{c}\text { Categorical } \\
\text { Variable }^{\mathbf{a}}\end{array}$ & $\mathbf{Q}_{\mathbf{b}}$ & $\mathbf{N}$ & $\boldsymbol{p}$-Value \\
\hline \multirow{6}{*}{ Rice } & Bio & 226.76 & 57 & 0.0006 & & Bio & 55.01 & 55 & 0.4742 \\
& Yie & 1263.65 & 322 & 0.0002 & Yie & 482.68 & 317 & 0.0000 \\
& GW & 618.72 & 359 & 0.0050 & & GW & 336.01 & 280 & 0.0240 \\
& GNPP & 853.73 & 288 & 0.0007 & Wheat & GNPP & 573.16 & 251 & 0.0003 \\
& PNPU & 848.35 & 284 & 0.0078 & & PNPU & 269.62 & 151 & 0.0008 \\
& FP & 1674.41 & 245 & 0.0006 & & PL & 33.54 & 44 & 0.1226 \\
& PL & 1695.34 & 67 & 0.0001 & PH & 246.88 & 74 & 0.0092 \\
& PH & 470.23 & 151 & 0.0051 & - & - & - & - \\
\hline
\end{tabular}

a Abbreviations for the agronomic traits are described in Table 2, $\mathrm{Q}_{\mathrm{b}}$ : Heterogeneity, N: number of samples.

\section{Results}

\subsection{Overall Effects of Drought on Wheat and Rice}

Across all the studies, drought significantly decreased the agronomic traits of wheat and rice (see Figure 1) with biomass and yield showing the largest decreases. Drought decreased wheat biomass and yield by $25.0 \%$ and $27.5 \%$, respectively, and decreased rice biomass and yield by $25.2 \%$ and $25.4 \%$, respectively. The large yield loss in wheat was caused by a combination of decreases in GW $(-10.6 \%)$, GNPP $(-15.8 \%)$, PNPU $(-11.2 \%)$, and PL $(-14.9 \%)$. Similarly, in rice, the large yield loss was caused by a combination of decreases in GW $(-6.3 \%)$, GNPP $(-9.2 \%)$, PNPU $(-9.1 \%)$, PL $(-0.4 \%)$, and FP $(-17.0 \%)$. Significant differences were found only in PL and GNPP between wheat and rice (see Figure 1). However, the drought decreased wheat growth more than rice growth in most agronomic traits except for the FP that had no comparison data.

\subsection{Effect of Stress Intensity on Rice and Wheat in Response to Drought}

The detrimental effect of drought on agronomic traits was progressively greater as stress intensity increased with no exceptions in both rice and wheat (see Figure 2). The reductions of rice biomass under mild, moderate, and severe stress were $12.5 \%, 18.0 \%$, and $35.5 \%$, respectively (see Figure 2a). Additionally, the reductions in wheat biomass were $11.0 \%, 21.0 \%$, and $34.7 \%$, respectively (see Figure $2 b$ ). Drought decreased rice yield under mild, moderate, and severe stress by $17.0 \%, 27.8 \%$, and $32.0 \%$, respectively. Drought also decreased wheat yield by $21.0 \%, 25.8 \%$, and $32.0 \%$, respectively. Other variables such as FP, PL, GNPP, PNPU, and GW showed significantly larger reductions under severe stress than under mild stress. However, the GNPP, GW, and PH of wheat showed no differences between mild stress and moderate stress. 


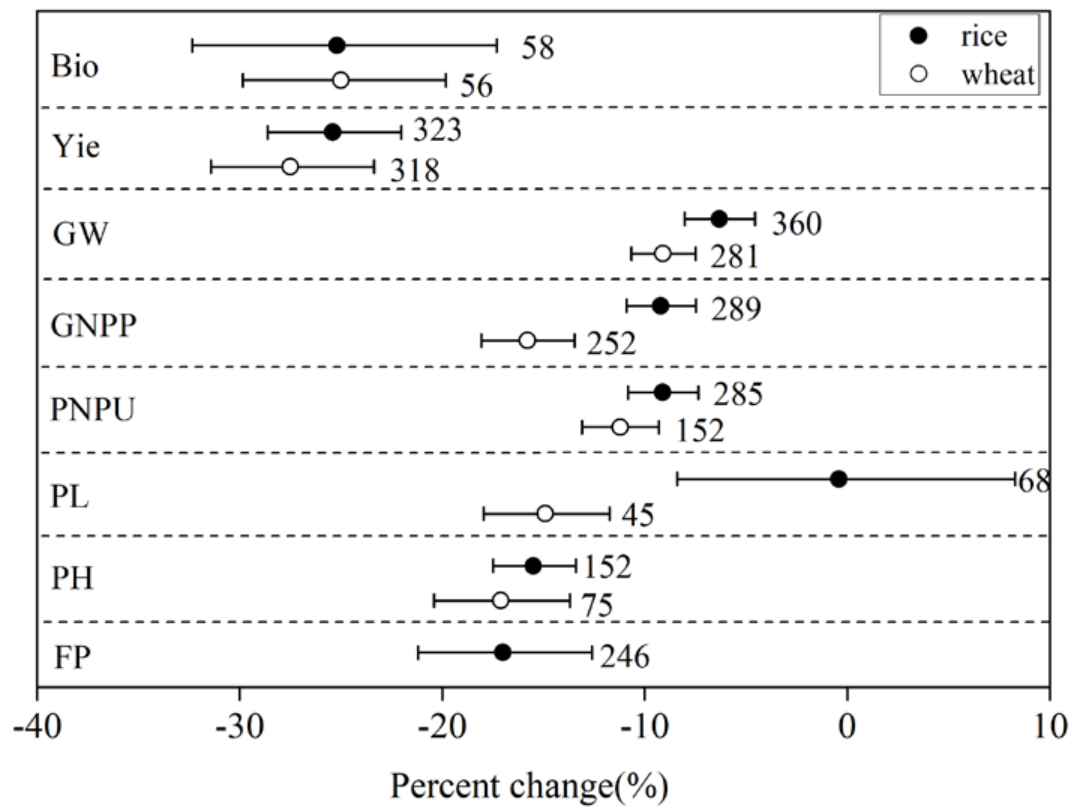

Figure 1. Effect of drought on the agronomic traits of rice and wheat. Numbers near the symbols specify the number of data points and the error bars indicate a 95\% confidence interval. Abbreviations for the agronomic traits are described in Table 2.

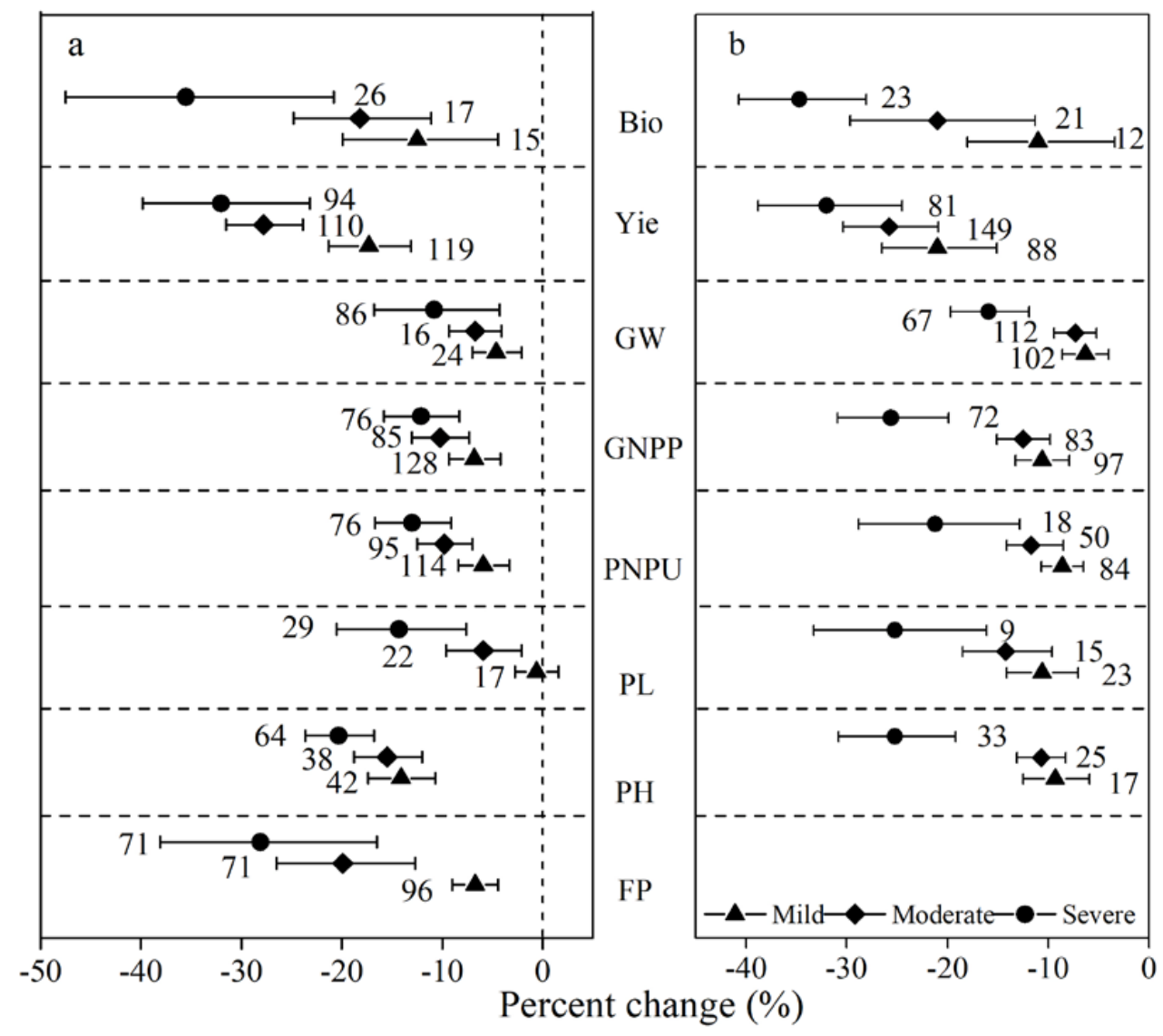

Figure 2. Response of rice and wheat to drought under different stress intensities. Numbers near the symbols specify the number of data points and the error bars indicate a $95 \%$ confidence interval. Abbreviations for the agronomic traits are described in Table 2 (a) Rice, (b) Wheat. 


\subsection{Effect of the Rooting Environment on Rice and Wheat in Response to Drought}

From Figure 3, rice plants grown in the field showed the largest reductions in agronomic traits than rice plants grown in pots or plots in the greenhouse. Rice biomass and yield decreased the most by $40.0 \%$ and $37.4 \%$, respectively, when grown in the field. However, rice showed the smallest reductions in yield, GW, GNPP, and PNPU $(-6.0 \%,-3.0 \%,-1.3 \%$, and $-6.0 \%$, respectively) when they were grown in plots (see Figure 3a). In contrast, wheat agronomic traits (e.g., biomass, yield, GW, GNPP, and PL) decreased the most $(-32.5 \%,-30.3 \%,-12.0 \%,-19.5 \%$, and $-15.6 \%$, respectively) and the least $(-16.6 \%,-22.6 \%,-3.4 \%,-11.4 \%$, and $-12.0 \%$, respectively) when they were grown in pots and in the field, respectively (see Figure 3b). However, we could not rule out the systematic errors of $\mathrm{PH}$ and PL because there were too few sample sizes (see Figure $3 b$ ).

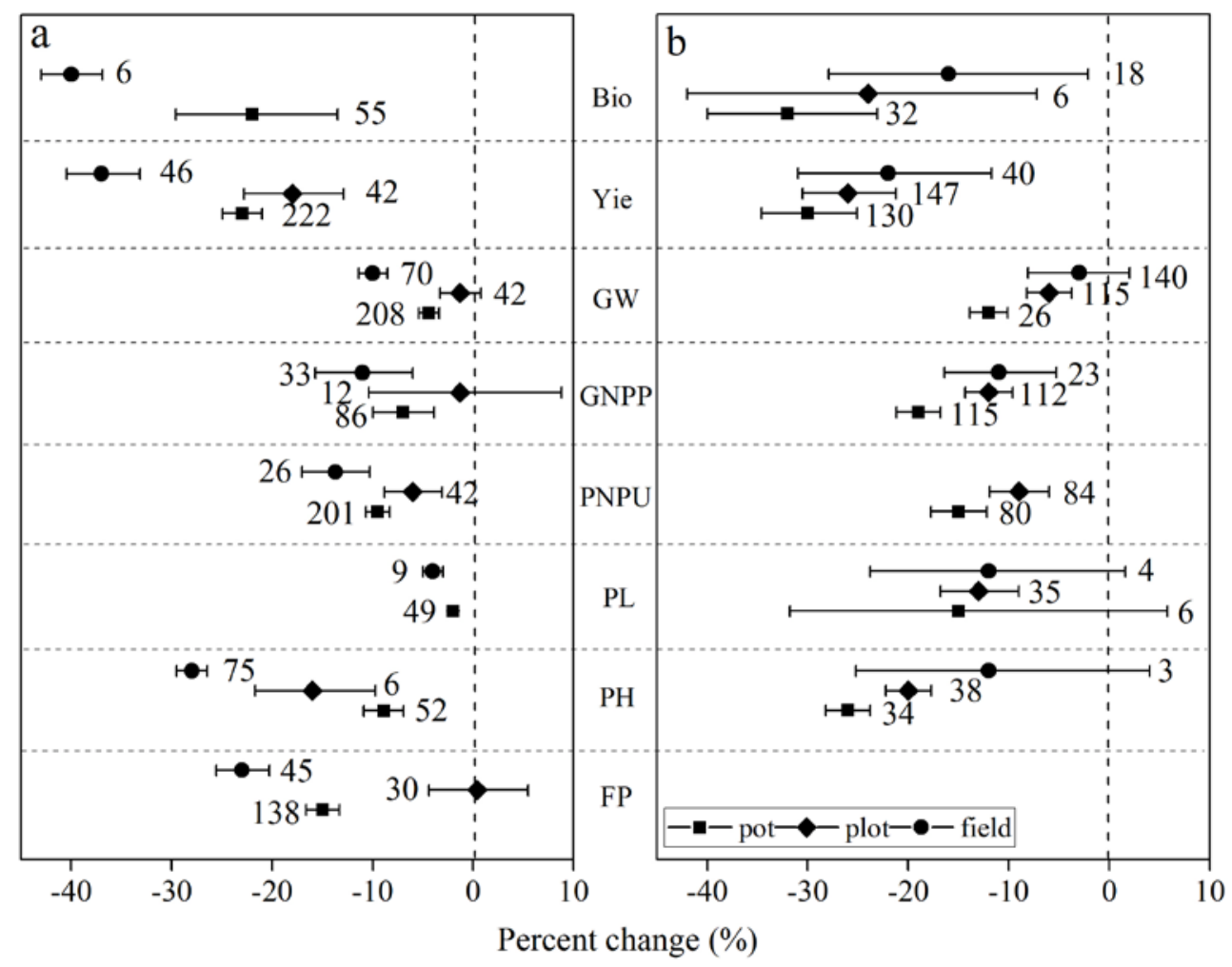

Figure 3. Response of rice and wheat to drought in different rooting environments. Numbers near the symbols specify the number of data points and the error bars indicate a $95 \%$ confidence interval (CI). Abbreviations for the agronomic traits are described in Table 2 (a) Rice, (b) Wheat.

\subsection{Effect of Growth Stages on Rice and Wheat in Response to Drought}

The effect of growth stages on rice varied among the variables (see Figure 4a). Rice biomass showed larger reductions during the tillering stage $(-31.0 \%)$ and booting stage $(-32.5 \%)$ under drought conditions. The smallest reductions of yield and GW occurred during the tillering stage $(-20.0 \%$ and $-0.2 \%$, respectively) and the largest occurred during the filling stage $(-31.5 \%$ and $-9.7 \%$, respectively) in addition to the decrease in GW $(-14.7 \%)$ during the complete growth cycle. There were diminishing decreases in rice GNPP and PNPU with rice growth, which shows the largest decreases during the tillering and booting stages but the smallest decreases during the filling stage. Droughts that occurred during the booting stage had the greatest negative effect on rice PL. Rice PH decreased the most $(20.0 \%)$ during the complete growth cycle and decreased by $3.2 \%$ during the tillering stage. FP decreased the most (26.3\%) during the filling stage. 


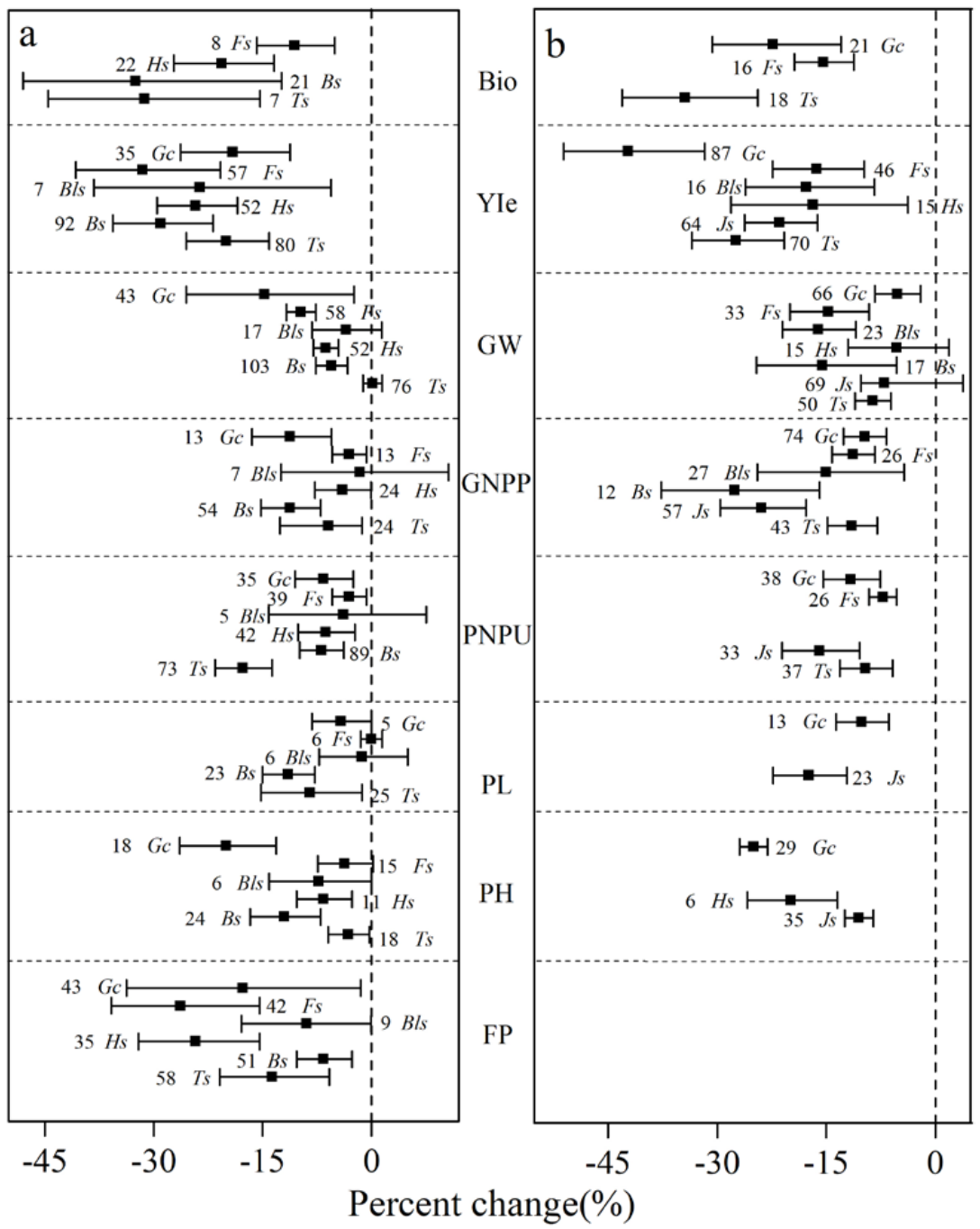

Figure 4. Response of rice and wheat to drought at different growth stages. Numbers near the symbols specify the number of data points and the error bars indicate a $95 \%$ confidence interval.

Most variables of wheat (see Figure $4 \mathrm{~b}$ ) showed significant decreases during different growth stages. Only GW did not decrease significantly during the jointing stage and heading stage under the drought condition with $95 \%$ confidence intervals overlapping with zero. Drought decreased wheat biomass the most by $34.4 \%$ at the tillering stage. Drought decreased wheat yield the most during the complete growth cycle, which was achieved from a combination of decreases during the tillering stage $(-27.4 \%)$, the jointing stage $(-21.4 \%)$, the heading stage $(-16.8 \%)$, the blooming stage $(-17.7 \%)$, and the filling stage $(-16.3 \%)$. Biomass, PNPU, GUPP, and GW did not indicate a clear changing trend with the growth and development of wheat. Wheat PNPU showed the largest decrease $(-15.8 \%)$ during the jointing stage and the smallest decrease $(-7.0 \%)$ during the filling stage, which owes to drought. Wheat GNPP showed the largest decrease $(-27.6 \%)$ during the booting stage. Wheat $\mathrm{PH}$ decreased the most $(-25.0 \%)$ during the complete growth cycle.

\subsection{Difference of the Effects of Drought between Wheat Types}

Significant differences were found only in $\mathrm{PH}, \mathrm{GW}$, and yield between winter and spring wheat (see Figure 5). The spring wheat $(-32.0 \%)$ had a much larger decrease in $\mathrm{PH}$ than that of the winter wheat $(-12.0 \%)$. The GW of spring wheat showed a negligible decrease by $0.5 \%$. However, the GW of winter wheat decreased by $10.0 \%$. Little differences were shown in Bio, GNPP, and PNPU between 
winter and spring wheat. Spring wheat showed a larger decrease in GNPP than winter wheat did with regard to drought.

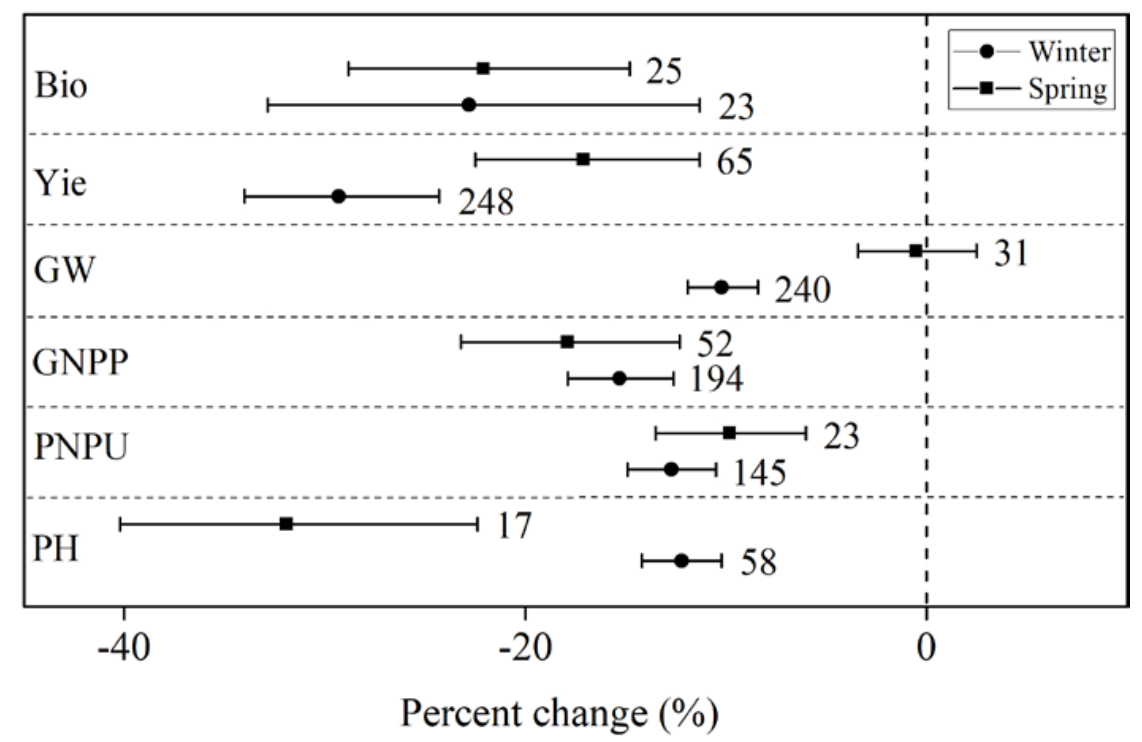

Figure 5. Effect of drought on winter and spring wheat. Numbers near the symbols specify the number of data points and the error bars indicate a 95\% confidence interval. Abbreviations for the agronomic traits are described in Table 2.

\section{Discussion}

\subsection{How Crop Grain Yield is Reduced by Drought and How Yield Components Respond to Drought}

The results suggested that there were differences among agronomic trait responses between rice and wheat under drought conditions (see Figure 1). Wheat demonstrated a $27.5 \%$ yield reduction and rice showed a $25.4 \%$ yield reduction despite the variations in the response observed in different studies (see Table 1). Variability of wheat and rice yields might be related to variations in plant physiological traits since different cereal species adopt different adaptation mechanisms to drought [12]. Yield loss has been attributed to the reduction in photosynthetic activity and lower supply of assimilates that support reproductive development and seed growth $[8,25]$. Some plants such as wheat can adapt to drought conditions via high osmotic adjustment and recovery after stress. Furthermore, wheat has the ability to shed their old leaves and maintain the carbon assimilation in their new, young leaves [28]. Rice is more sensitive to drought with a larger reduction in yield when compared to wheat (e.g., $\sim 40 \%$ water deficit) [12]. Molecular genetics have discovered many quantitative trait loci that affect yield under drought conditions [29]. To avoid this large yield loss, the practical application of new molecular knowledge and tools for screening selection and improvement of rice germplasm for drought is required [30].

The most important component responsible for plant biomass reduction of wheat and rice was the decrease in grain yield, which was followed by a decrease in the PH. The yield reductions under drought conditions attributed to the decreases in yield components (e.g., PNPU, GW, weight of grains/spike, and biological yield) [21]. The component contributing the most to yield reduction varied between wheat and rice. For instance, PL and GNPP were the two most important components related to yield reduction in wheat (see Figure 1). However, GW and PNPU also showed significant decreases due to drought. This is consistent with previous studies where drought was shown to have a greater influence on grain number, which largely accounts for the decline in wheat yield [31]. Drought has an extremely adverse effect on meiosis and anthesis, which directly affects grain number. This causes a substantial reduction in grain yield [29]. Moreover, pollen becomes sterile when drought 
occurs during the early microspore stage of pollen development, which would reduce the grain number [32]. This phenomenon might indicate that the longer the panicle is, the more wheat grains it has. In contrast, the decrease in FP contributed the greatest addition to the rice yield reduction. It has been suggested that grain filling is damaged the most by drought over the complete rice growth cycle. Similar results have been reported in wheat influenced by elevated levels of $\mathrm{O}_{3}$ [25].

\subsection{The Impact of Growth Stages, Stress Intensities, Rooting Environment, and Wheat Types on Crop Agronomic Traits in Response to Drought}

Growth stages. Yield is basically the complex integration of the different growth stages. The negative influence of drought on the yield mainly depends on the sensitivity of the plant to drought during different growth stages [8]. For instance, drought occurring during the vegetative phase reduced the rice yield by $21-50.6 \%$ whereas severe drought during the flowering stage reduced the rice yield by $42-83.7 \%$ and moderate to severe drought during the whole reproductive stage reduced the rice yield by $51-90.6 \%$ (see Table 4 ). From the present meta-analysis study, rice was more sensitive to drought during the reproductive phases (e.g., blooming stage, filling stage, and maturity) than during the vegetative phases (e.g., tillering stage, jointing stage, and so on), which is shown in Figure 4. Previous studies have confirmed that greater yield reduction occurred during the reproductive stage [12] because crops barely recovered from the damage caused by drought. Drought during the vegetative phase limited carbohydrate synthesis for cell division and expansion via stomatal closure and partial inhibition of photosynthesis. Yet this was considered reparable [33]. The results obtained by Sarvestani et al. [34] proved the above theoretical conclusion that a water deficit during the flowering stage produced a lower rice yield by $50 \%$ when compared to a water deficit during the vegetative and grain filling stages. PNPU and GNPP were more adversely influenced during the vegetative phase (e.g., tillering stage and booting stage) than during the reproductive phase (see Figure 4) because the drought limited cell division for tillers, panicles, and grains. These results are supported by the results from Boonjung et al. [35] in which the reduction in rice yield of about $30 \%$ was due to reduced PNPU and the number of grains per panicle. In this case, the drought occurred during the vegetative stage.

However, some exceptions were found in wheat in response to drought. Wheat had similar sensitivity to drought during the vegetative and reproductive phases with no significant differences in agronomic traits found in the different stages (see Figure 4). This is in agreement with the global synthesis of wheat in response to drought $[8,16]$. Wheat is sensitive to drought during the vegetative phase (e.g., tillering stage) because drought limits the development of the root system, which results in decreased leaf area, leaf number per plant, leaf size, and leaf longevity [35]. Drought occurring during the tillering stage decreased wheat yield by $47.0 \%$, which is much larger than during the booting stage and its $21.0 \%$ decrease [35]. This is supported by the results from a study that only considered normal tillers instead of a combination of late and normal tillers [13]. Wheat can produce late tillers when the early-season drought ends, which contribute to the final grain yield [13]. In the present meta-analysis, drought from the jointing stage to maturity reduced wheat yield significantly by decreasing GNPP, PL, and PNPU. When drought occurred in the mid-season (e.g., between the jointing stage and anthesis), its effect on wheat head size (i.e., the number of spikelet per spike) might be irreversible since late-emerging tillers would not contribute to yield [36]. It is more critical when drought occurred during the flowering and grain-filling stages than other stages and resulted in substantial yield reduction due to reduced rates of net photosynthesis owing to metabolic limitations (e.g., oxidative damage to chloroplasts and stomatal closure) and poor grain set and development [9,37]. The results show that post anthesis mild drought decreased wheat yields by $1-30 \%$ while a prolonged mild drought during the flowering and grain filling stages reduced grain yields by $58-92 \%$ [9]. 
Table 4. Reductions in agronomic traits in rice caused by drought stress.

\begin{tabular}{cccc}
\hline Growth Stage & Drought Stress & Yield Reduction (\%) $\mathbf{a}^{\mathbf{a}}$ & Reference \\
\hline Vegetative stage & Severe stress & 50.6 & Guan et al., 2010 [36] \\
Vegetative stage & Water stress & 21 & Sarvestani et al., 2008 [34] \\
Flowering stage & Severe stress & 42 & Pinheiro et al., 2000 [37] \\
Flowering stage & Severe stress & $76.7-83.7$ & Puteh et al., 2013 [38] \\
Flowering stage & Water stress & 50 & Sarvestani et al., 2008 [34] \\
Flowering stage & Severe stress & $>70$ & Shamsudin et al., 2016 [39] \\
Reproductive stage & Moderate stress & $51-57$ & Dixit et al., 2014 [40] \\
Reproductive stage & Severe stress & 70 & Dixit et al., 2014 [40] \\
Reproductive stage & Moderate stress & 90.6 & Dixit et al., 2012 [41] \\
Reproductive stage & Severe stress & 63.1 & Dixit et al., 2012 [41] \\
Reproductive stage & Severe stress & 74.5 & Guan et al., 2010 [36] \\
Reproductive stage & Moderate to severe stress & $51-60$ & Swamy et al., 2017 [42] \\
\hline & a Yield reduction are percent change of yield loss effected by drought.
\end{tabular}

Drought stress intensity. The severity of water stress variably affected yield-related traits in rice and wheat. The reductions of yield and its components in both rice and wheat under severe stress were significantly greater than that under mild stress (see Figure 2). In the present meta-analysis study, the current severe drought decreased wheat yield production by more than $40 \%$ and rice yield production by $30 \%$. Considering the changing trends of climate change, drought is predicted to be more intense and frequent in many regions in the future [19] with global agricultural drought frequency and area increased by $50-200 \%$ in a relative sense during the 21 st century so far [20]. Moderate and severe drought levels based on current climate standards will become the norm in the future [43] with a corresponding doubling of the spatial extent of severe soil moisture deficits and the frequency of short-term droughts at the end of the 21st century. Future droughts could produce a further lowering in yield and other agronomic traits when compared to the current drought. A previous study proved that moderate droughts ( $40 \%$ water reduction) and severe water deficits ( $>50 \%$ water reduction) caused different reductions in grain number, number of fertile ears per unit area, and number of grains per ear [44]. Therefore, severe droughts should be avoided during the tillering, booting, and flowering stages because drought limits the cell divisions for tillers, panicles, and grains [22,34]. These results might be explained by the oxidative damage to photo-assimilatory machinery under severe stress and the different reduced rates of carbon fixation [45]. A meta-analysis of plant leaf gas exchange showed that drought decreased net photosynthesis by $64 \%$ under severe stress, which was more than two times the decrease $(-28.0 \%)$ under mild stress [46]. The damage from a severe drought to different growth stages is irreversible and unrecoverable.

Rooting environment. Root system architecture is one of the most important contributors to drought resistance in crops [8]. A well-developed root system is key to ensuring stable and high yields under drought [47] and the greater root length in deeper soil layers has been shown to increase yield by allowing more water extraction [48]. However, most of the root screening is restricted in artificial growth media, which limits inference to field grown crops [49]. The results from the present meta-analysis study showed that the rooting environment had a significant influence on wheat and rice yield. Rice grown in fields showed a larger decreased yield in response to drought when compared to rice grown in pots. Since rice is characterized by a shallower and more fibrous root system than wheat [50], it has limited water extraction below $60 \mathrm{~cm}$ [51]. The capacity of the pot (5 15 L) was acceptable for rice root development whereas rice grown in the field might have a competitive pressure of a water deficit from other plant individuals. The lateral root of rice showed greater development under drought [52], which would accelerate drought stress in $20 \mathrm{~cm}$ deep soil adverse to rice production. However, wheat grown in pots showed a larger decreased yield and yield-related traits than wheat grown in the field. This might be because the pot significantly limited the development of the wheat 
root systems, which were responsible for grain yield reductions in wheat because wheat roots could extend to an average of $113 \mathrm{~cm}$ deep and had less than $50 \%$ of their total root length in the top $20 \mathrm{~cm}$ of the soil [53]. Drought during the vegetative phase (e.g., tillering stage) limits root system development that leads to decreases in leaf area, leaf number per plant, leaf size, and leaf longevity [35].This aligns with the meta-analysis of wheat in response to elevated $\mathrm{O}_{3}$ that showed a larger decrease in biomass and yield for wheat grown in plots than those grown in the field [25].

Wheat types. It was assumed that the response of spring wheat to drought would be different to that of winter wheat. However, our meta-analysis assessment across all studies indicated that there was no significant difference between spring and winter wheat in terms of investigated parameters with an exception of PH and GW. Similar results were also found in a previous study [25] where there was no significant difference in yield and relative traits between spring and winter wheat in response to elevated $\mathrm{O}_{3}$ levels.

\section{Conclusions}

In the present meta-analysis study, we found that drought, which is an important limiting factor, decreased agronomic traits differently between wheat and rice among different growth stages. Rice demonstrated larger reductions in yield and in its components during the reproductive phase (e.g., blooming stage, filling stage, and maturity). Wheat exhibited similar reductions during the complete growth cycle. The rooting environment also affected the agronomic traits under drought conductions with opposite performance changes between wheat and rice. Based on these studies, future droughts could result in further decreases in yield and other agronomic traits than in the current drought. However, a drought is not the only element of global climate change that affects crop agronomic traits and it will interact with other factors such as precipitation, temperature, and increasing $\mathrm{CO}_{2}$ levels.

Supplementary Materials: The following are available online at http:/ / www.mdpi.com/1660-4601/15/5/839/s1, Table S1: The collected information used in the meta-analysis about effects of drought on rice and wheat.

Author Contributions: J.Z. and H.J. designed the study. J.Z., S.Z., and M.C. performed the data collection and analysis. J.Z., X.Z., C.P., X.L., M.Z., and J.J. interpreted the results and wrote the paper.

Acknowledgments: This research was supported partially from the NSF China Major Program (41601442, $41171324 \& 41501212)$ and the fundamental research project of MOST (2005DKA32306).

Conflicts of Interest: The authors declare no conflict of interest.

\section{References}

1. Lesk, C.; Rowhani, P.; Ramankutty, N. Influence of extreme weather disasters on global crop production. Nature 2016, 529, 84-87. [CrossRef] [PubMed]

2. Tilman, D.; Balzer, C.; Hill, J.; Befort, B.L. From the Cover: Global food demand and the sustainable intensification of agriculture. Proc. Natl. Acad. Sci. USA 2011, 108, 20260-20264. [CrossRef] [PubMed]

3. McGuire, S. WHO, World Food Programme, and International Fund for Agricultural Development. 2012. The State of Food Insecurity in the World 2012. Economic growth is necessary but not sufficient to accelerate reduction of hunger and malnutrition. Rome, FAO. Adv. Nutr. 2012, 4, 126-127. [CrossRef] [PubMed]

4. Ray, D.K.; Mueller, N.D.; West, P.C.; Foley, J.A. Yield Trends Are Insufficient to Double Global Crop Production by 2050. PLoS ONE 2013, 8, e66428. [CrossRef] [PubMed]

5. Wiltshire, A.J.; Kay, G.; Gornall, J.L.; Betts, R.A. The Impact of Climate, CO2 and Population on Regional Food and Water Resources in the 2050s. Sustainability 2013, 5, 2129-2151. [CrossRef]

6. Awika, J.M. Major Cereal Grains Production and Use around the World. ACS Symp. 2011, 1089, 1-13. [CrossRef]

7. Hatfield, J.L.; Prueger, J.H. Temperature extremes: Effect on plant growth and development. Weather Clim. Extrem. 2015, 10, 4-10. [CrossRef]

8. Farooq, M.; Hussain, M.; Siddique, K.H.M. Drought Stress in Wheat during Flowering and Grain-filling Periods. Crit. Rev. Plant Sci. 2014, 33, 331-349. [CrossRef] 
9. Matiu, M.; Ankerst, D.P.; Menzel, A. Interactions between temperature and drought in global and regional crop yield variability during 1961-2014. PLoS ONE 2017, 12, e0178339. [CrossRef] [PubMed]

10. Fahad, S.; Bajwa, A.A.; Nazir, U.; Anjum, S.A.; Farooq, A.; Zohaib, A.; Sadia, S.; Nasim, W.; Adkins, S.; Saud, S. Crop Production under Drought and Heat Stress: Plant Responses and Management Options. Front. Plant Sci. 2017, 8, 1147. [CrossRef] [PubMed]

11. Parry, M.L.; Canziani, O.F.; Palutikof, J.P.; Linden, P.J.V.D.; Hanson, C.E. Contribution of Working Group II to the Fourth Assessment Report of the Intergovernmental Panel on Climate Change. In Encyclopedia of Language and Linguistics; Elsevier: New York, NY, USA, 2007; Volume 12, pp. 171-175.

12. Daryanto, S.; Wang, L.; Jacinthe, P.A. Global synthesis of drought effects on cereal, legume, tuber and root crops production: A review. Agric. Water Manag. 2017, 179, 18-33. [CrossRef]

13. Daryanto, S.; Wang, L.; Jacinthe, P.A. Global Synthesis of Drought Effects on Maize and Wheat Production. PLoS ONE 2016, 11, e0156362. [CrossRef] [PubMed]

14. Spiertz, H. Challenges for crop production research in improving land use, productivity and sustainability. Sustainability 2013, 5, 1632-1644. [CrossRef]

15. Balla, K.; Rakszegi, M.; Li, Z.G.; Békés, F.; Bencze, S.; Veisz, O. Quality of winter wheat in relation to heat and drought shock after anthesis. Czech J. Food Sci. 2011, 29, 117-128. [CrossRef]

16. Tack, J.; Barkley, A.; Nalley, L.L. Heterogeneous effects of warming and drought on selected wheat variety yields. Clim. Chang. 2014, 125, 489-500. [CrossRef]

17. Carrijo, D.R.; Lundy, M.E.; Linquist, B.A. Rice yields and water use under alternate wetting and drying irrigation: A meta-analysis. Field Crop Res. 2017, 203, 173-180. [CrossRef]

18. Lafitte, H.R.; Yongsheng, G.; Yan, S.; Li, Z.K. Whole plant responses, key processes, and adaptation to drought stress: The case of rice. J. Exp. Bot. 2007, 58, 169-175. [CrossRef] [PubMed]

19. Trenberth, K.E.; Dai, A.; Schrier, G.V.D.; Jones, P.D.; Barichivich, J.; Briffa, K.R.; Sheffield, J. Global warming and changes in drought. Nat. Clim. Chang. 2014, 4, 17-22. [CrossRef]

20. Zhao, T.; Dai, A. Uncertainties in historical changes and future projections of drought. Part II: Model-simulated historical and future drought changes. Clim. Chang. 2017, 144, 535-548. [CrossRef]

21. Leilah, A.A.; Alkhateeb, S.A. Statistical analysis of wheat yield under drought conditions. J. Arid Environ. 2005, 61, 483-496. [CrossRef]

22. Boonjung, H.; Fukai, S. Effects of soil water deficit at different growth stages on rice growth and yield under upland conditions. 2. Phenology, biomass production and yield. Field Crop Res. 1996, 48, 47-55. [CrossRef]

23. Rosenberg, M.S.; Adams, D.C.; Gurevitch, J. Meta Win: Statistical Software for Meta-Analysis. Version 2; Sinauer Associates: Sunderland, MA, USA, 2000.

24. Elizabetha, A. Rice production in a changing climate: A meta-analysis of responses to elevated carbon dioxide and elevated ozone concentration. Glob. Chang. Biol. 2008, 14, 1642-1650. [CrossRef]

25. Feng, Z.; Kazuhiko, K.; Elizabetha, A. Impact of elevated ozone concentration on growth, physiology, and yield of wheat (Triticum aestivum L.): A meta-analysis. Glob. Chang. Biol. 2008, 14, 2696-2708. [CrossRef]

26. Hedges, L.V.; Gurevitch, J.; Curtis, P.S. The Meta-Analysis of Response Ratios in Experimental Ecology. Ecology 1999, 80, 1150-1156. [CrossRef]

27. Song, X.; Peng, C.; Zhou, G.; Jiang, H.; Wang, W. Chinese Grain for Green Program led to highly increased soil organic carbon levels: A meta-analysis. Sci. Rep. 2014, 4, 4460. [CrossRef] [PubMed]

28. Monneveux, P.; Jing, R.; Misra, S.C. Phenotyping wheat for adaptation to drought. Front. Plant Sci. 2012, 3, 247-259.

29. Cattivelli, L.; Rizza, F.; Badeck, F.W.; Mazzucotelli, E.; Mastrangelo, A.M.; Francia, E.; Marè, C.; Tondelli, A.; Stanca, A.M. Drought tolerance improvement in crop plants: An integrated view from breeding to genomics. Field Crop Res. 2008, 105, 1-14. [CrossRef]

30. Ramegowda, V.; Basu, S.; Krishnan, A.; Pereira, A. Rice GROWTH UNDER DROUGHT KINASE Is Required for Drought Tolerance and Grain Yield under Normal and Drought Stress Conditions. Plant Physiol. 2014, 166, 1634-1645. [CrossRef] [PubMed]

31. Dolferus, R.; Ji, X.; Richards, R.A. Abiotic stress and control of grain number in cereals. Plant Sci. 2011, 181, 331-341. [CrossRef] [PubMed]

32. Ji, X.; Shiran, B.; Wan, J.; Lewis, D.C.; Jenkins, C.L.; Condon, A.G.; Richards, R.A.; Dolferus, R. Importance of pre-anthesis anther sink strength for maintenance of grain number during reproductive stage water stress in wheat. Plant Cell Environ. 2010, 33, 926-942. [CrossRef] [PubMed] 
33. Barnabás, B.; Jäger, K.; Fehér, A. The effect of drought and heat stress on reproductive processes in cereals. Plant Cell Environ. 2008, 31, 11-38. [CrossRef] [PubMed]

34. Sarvestani, Z.T.; Pirdashti, H.; Sanavy, S.A.; Balouchi, H. Study of water stress effects in different growth stages on yield and yield components of different rice (Oryza sativa L.) cultivars. Pak. J. Biol. Sci. 2008, 11, 1303-1309. [CrossRef] [PubMed]

35. Boonjung, H.; Fukai, S. Effects of soil water deficit at different growth stages on rice growth and yield under upland conditions. 1. Growth during drought. Field Crop Res. 1996, 48, 37-45. [CrossRef]

36. Guan, Y.S.; Serraj, R.; Liu, S.H.; Xu, J.L.; Ali, J.; Wang, W.S.; Venus, E.; Zhu, L.H.; Li, Z.K. Simultaneously improving yield under drought stress and non-stress conditions: A case study of rice (Oryza sativa L.). J. Exp. Bot. 2010, 61, 4145-4156. [CrossRef] [PubMed]

37. Pinheiro, B.D.S.; Austin, R.B.; Carmo, M.P.D.; Hall, M.A. Carbon isotope discrimination and yield of upland rice as affected by drought at flowering. Pesqui. Agropecu. Brasil. 2000, 35, 1939-1947. [CrossRef]

38. Puteh, A.B.; Saragih, A.A.; Ismail, M.R.; Mondal, M.M.A. Grain yield of cultivated and weedy rice to water stress at reproductive stage. J. Food Agric. Environ. 2013, 11, 742-746.

39. Shamsudin, N.A.A.; Swamy, B.P.M.; Ratnam, W.; Cruz, M.T.S.; Sandhu, N.; Raman, A.K.; Kumar, A. Pyramiding of drought yield QTLs into a high quality Malaysian rice cultivar MRQ74 improves yield under reproductive stage drought. Rice 2016, 9, 21. [CrossRef] [PubMed]

40. Dixit, S.; Singh, A.; Ma, T.S.C.; Maturan, P.T.; Amante, M.; Kumar, A. Multiple major QTL lead to stable yield performance of rice cultivars across varying drought intensities. BMC Genet. 2014, 15, 16. [CrossRef] [PubMed]

41. Dixit, S.; Swamy, B.P.M.; Vikram, P.; Ahmed, H.U.; Sta Cruz, M.T.; Amante, M.; Atri, D.; Leung, H.; Kumar, A. Fine mapping of QTLs for rice grain yield under drought reveals sub-QTLs conferring a response to variable drought severities. Theor. Appl. Genet. 2012, 125, 155-169. [CrossRef] [PubMed]

42. Swamy, B.P.M.; Shamsudin, N.A.A.; Rahman, S.N.A.; Mauleon, R.; Ratnam, W.; Sta Cruz, M.T.; Kumar, A. Association Mapping of Yield and Yield-related Traits Under Reproductive Stage Drought Stress in Rice (Oryza sativa L.). Rice 2017, 10, 21. [CrossRef] [PubMed]

43. Wang, L.; Chen, W. A CMIP5 multimodel projection of future temperature, precipitation, and climatological drought in China. Int. J. Climatol. 2014, 34, 2059-2078. [CrossRef]

44. Giunta, F.; Motzo, R.; Deidda, M. Effect of drought on yield and yield components of durum wheat and triticale in a Mediterranean environment. Field Crop Res. 1993, 33, 399-409. [CrossRef]

45. Farooq, M.; Wahid, A.; Kobayashi, N.; Fujita, D.; Basra, S.M.A. Plant drought stress: Effects, mechanisms and management. Agron. Sustain. Dev. 2009, 29, 185-212. [CrossRef]

46. Yan, W.; Zhong, Y.; Shangguan, Z. A meta-analysis of leaf gas exchange and water status responses to drought. Sci. Rep. 2016, 6, 20917. [CrossRef] [PubMed]

47. Dodd, I.C.; Whalley, W.R.; Ober, E.S.; Parry, M.A. Genetic and management approaches to boost UK wheat yields by ameliorating water deficits. J. Exp. Bot. 2011, 62, 5241-5248. [CrossRef] [PubMed]

48. Manschadi, A.M.; Christopher, J.; Devoil, P.; Hammer, G.L. The role of root architectural traits in adaptation of wheat to water-limited environments. Funct. Plant Biol. 2006, 33, 823-837. [CrossRef]

49. Nakhforoosh, A. Recent approaches in screening methodology for drought resistance. Agric. Vet. Sci. Nutr. Nat. Resour. 2013, 8, 1-14. [CrossRef]

50. Gowda, V.R.P.; Henry, A.; Yamauchi, A.; Shashidhar, H.E.; Serraj, R. Root biology and genetic improvement for drought avoidance in rice. Field Crop Res. 2011, 122, 1-13. [CrossRef]

51. Fukai, S.; Inthapan, P. Growth and yield of rice cultivars under sprinkler irrigation in south-eastern Queensland. 1. Effects of sowing time. Aust. J. Exp. Agric. 1988, 28, 237-242. [CrossRef]

52. Kameoka, E.; Suralta, R.R.; Mitsuya, S.; Yamauchi, A. Developmental Plasticity of Rice Root System Grown under Mild Drought Stress Condition with Shallow Soil Depth; Comparison between Nodal and Lateral roots. Plant Prod. Sci. 2016, 19, 411-419. [CrossRef]

53. Hamblin, A.P. Root characteristics of some temperate legume species and varieties on deep, free-draining entisols. Aust. J. Agric. Res. 1985, 36, 63-72. [CrossRef]

(C) 2018 by the authors. Licensee MDPI, Basel, Switzerland. This article is an open access article distributed under the terms and conditions of the Creative Commons Attribution (CC BY) license (http:// creativecommons.org/licenses/by/4.0/). 